\title{
Non-thrombocytopenic purpura and acute glomerulonephritis after indomethacin therapy
}

\author{
F. P. MARSH, ${ }^{*}$ JOHN R. ALMEYDA, $\dagger$ AND I. S. LEVY $§$ \\ From The London Hospital
}

Glomerulonephritis has not previously been attributed to indomethacin. Two patients are reported below in whom non-thrombocytopenic purpura and a severe glomerulonephritis developed during or shortly after indomethacin therapy.

\section{Case reports}

Case 1, a 76-year-old previously fit spinster, was treated for 2 weeks with indomethacin, $25 \mathrm{mg}$. four times daily, for aching of her feet and legs of several months' duration. She had not taken any other drugs. One week after starting treatment she lost her appetite and her voice

became husky. Two days after the end of treatment her legs became red and swollen and were covered by a non-irritating maculo-papular purpuric eruption, with haemorrhagic vesicles and ulcers, which spread to buttocks and lower trunk (Fig. 1).

On admission to The London Hospital she had a temperature of $99 \cdot 8^{\circ} \mathrm{F}$. and there was some mucopus in the pharynx. Apart from the rash, oedematous legs, and gross obesity, examination was unremarkable; the blood pressure was normal.

A clinical diagnosis of allergic vasculitis was made and was supported by the histological appearance of a skin biopsy. She had a mild normochromic anaemia and a neutrophil leucocytosis. Platelet count, bleeding, clotting, prothrombin, and partial thromboplastin times were

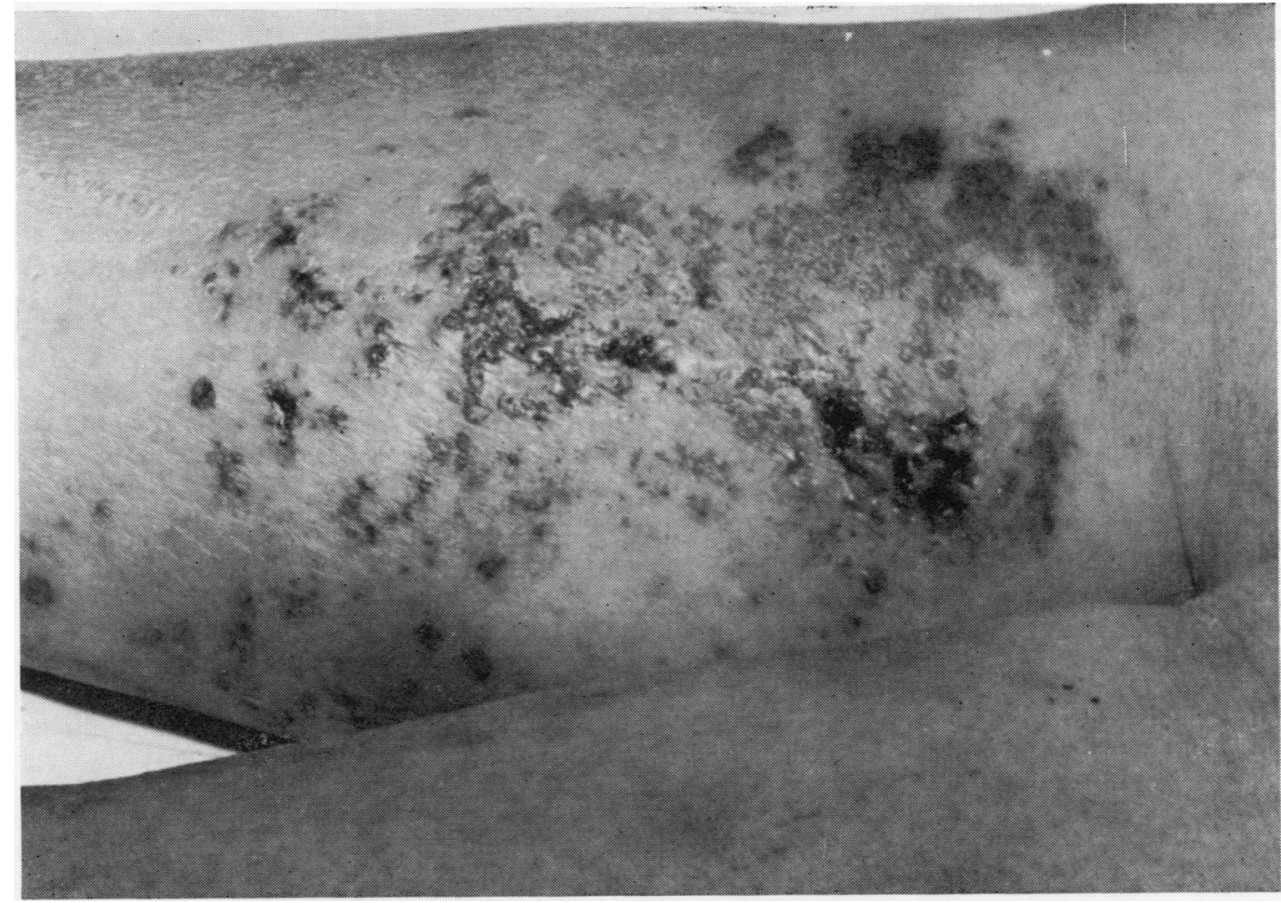

FIG. 1 Case 1. Postero-medial view of thighs, showing purpura, haemorrhagic vesicles, and erosions.

- Senior Lecturer, Medical Unit, The London Hospital, London, E.1.

4 Senior Registrar, Department of Dermatology, The London Hospital, London, E.1.

Senior House Officer, Department of Morbid Anatomy, The London Hospital London, E.1.

Present address: Moorfields Eye Hospital, London, E.C.1.

Accepted for publication May 6, 1971 . 
normal, as were liver function tests, S.G.O.T. and electrophoresis of plasma proteins. An antinuclear factor (ANF) test was negative. She had heavy proteinuria and many granular and hyaline casts in the urine, which was sterile. Plasma urea was $83 \mathrm{mg} . / 100 \mathrm{ml}$. No streptococci were cultured from skin lesions or sputum, blood culture was sterile, and antistreptolysin-O titre was only 50 units per $\mathrm{ml}$.

\section{Treatment}

She was given ampicillin, cloxacillin, gentamicin cream, and a 500-calorie diet; the intermittent pyrexia subsided over several days. It was impossible to measure urine output because of her obesity and debility, but a diuresis was suggested by a weight loss of one stone in the first week, her weight thereafter remaining steady. However, the plasma urea rose to $163 \mathrm{mg} . / 100 \mathrm{ml}$. and plasma creatinine to $1.9 \mathrm{mg} . / 100 \mathrm{ml}$. despite dietary protein restriction to $20 \mathrm{~g}$. per 24 hours; there was no clinical evidence of salt and water depletion.

\section{Termination}

Two weeks after admission the patient suddenly died.

\section{Necropsy}

A large pulmonary embolus was found. There was haemorrhagic mottling of the kidneys which were otherwise macroscopically normal; microscopically many of the glomeruli showed changes of a proliferative glomerulonephritis, and there were occasional epithelial crescents (Fig. 2) and tuft necroses as well as fibrinoid changes in the afferent arterioles. There were only minimal osteoarthritic changes in the joints.

Case 2, a 59-year-old man, presented at Stoke Mandeville Hospital in May, 1967, with a seronegative non-erosive arthropathy. He was treated with indomethacin, $25 \mathrm{mg}$. twice daily by mouth and $100 \mathrm{mg}$. each night by suppository, aloxiprin 1.2 to $5.4 \mathrm{~g}$. daily, and occasional dihydrocodeine tablets. Between November, 1967, and March, 1968, he received $1 \mathrm{~g}$. sodium aurothiomalate and, towards the end of this course of treatment, prednisolone $5 \mathrm{mg}$. each night; the other analgesics were unchanged apart from a temporary withdrawal of indomethacin suppositories and he received no other drugs.

Six weeks after the gold therapy had ended he was admitted to hospital with purpura of sudden onset involving the trunk and limbs (Fig. 3, opposite), haematuria, haematemesis, and abdominal pain and tenderness. He was apyrexial and normotensive and his joints were clinically normal. He was slightly anaemic and had a mild neutrophil leucocytosis. Platelet count and aggregation by A.D.P. were normal as was a kaolin-cephalin test. An LE-cell preparation and a Hyland LE test were negative. No pathogens were cultured from a throat swab. Many red cells and an increased number of leucocytes, but no casts, were seen on microscopy of the urine, which contained $60 \mathrm{mg}$. protein per $100 \mathrm{ml}$. and was sterile. Liver function tests and electrolytes were normal and the plasma urea was $53 \mathrm{mg} . / 100 \mathrm{ml}$. Plasma albumin was $2.9 \mathrm{~g} . / 100 \mathrm{ml}$. Biopsy of a skin lesion revealed a perivascular infiltrate, mainly in the upper dermis, consisting of polymorphs, lymphocytes, and red cells. A barium meal suggested a gastric ulcer.

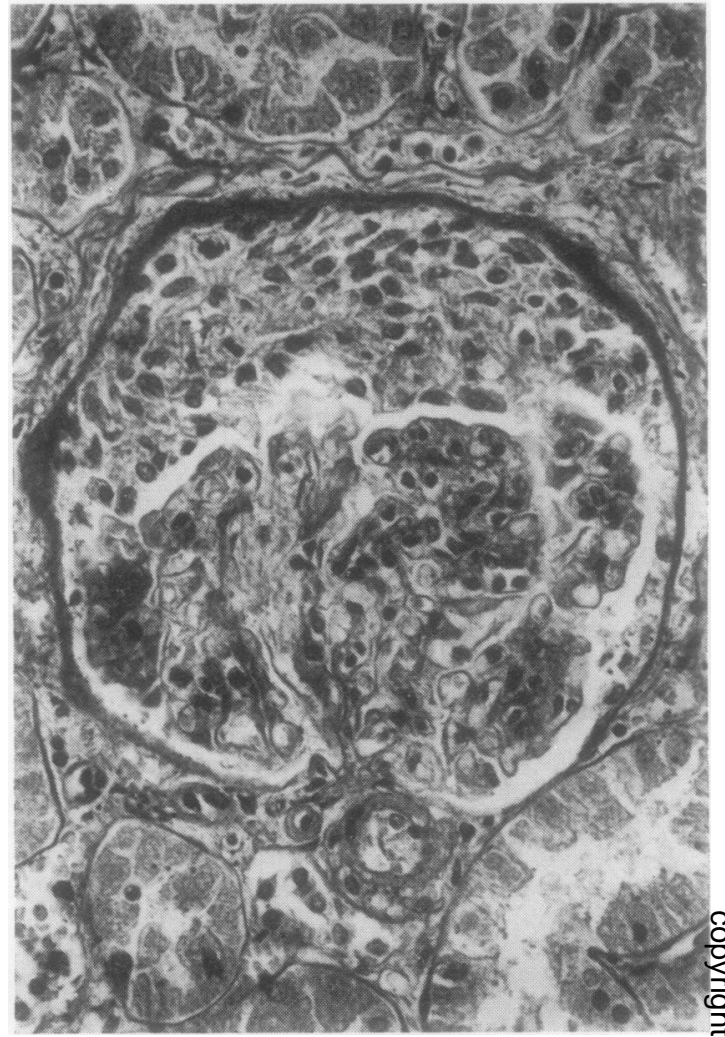

FIG. 2 Case 1. Histology of kidney at necropsy, showing crescent formation and periglomerular fibrosis. Haematoxylin and eosin. $\times 200$

Treatment with indomethacin was stopped, and he was given dimercaprol (30 ml. over 6 days) and ACTH for possible gold toxicity. The rash improved and he was discharged on ACTH only, to be readmitted within a fortnight with oedema of the limbs, abdomen, and face, pulmonary congestion, and a pleural effusion; no fresh purpura had occurred. Proteinuria had increased to 520 $\mathrm{mg} . / 100 \mathrm{ml}$. and his urine now contained granular casts as well as many red and white cells. Plasma urea had increased to $222 \mathrm{mg}$. $/ 100 \mathrm{ml}$. The antistreptolysin-O titre was less than 200 units $/ \mathrm{ml}$. and no pathogens were cultured from a further throat swab.

\section{Treatment}

He was treated with frusemide, and a low protein, low salt diet, and his steroids were reduced; he had a temporary diuresis but the plasma urea continued to rise. Biopsies of rectum and liver showed no evidence of amyloid nor any other significant abnormality. A trial of Arvin therapy, given in case renal vein thrombosis had occurred, was abandoned after several days because of melaena, and peritoneal dialysis became necessary. He was transferred to The London Hospital. Tomography suggested that the kidneys were of normal size and a renal biopsy showed evidence of an active glomerulonephritis with epithelial crescents, focal tuft necroses, fibrinoid necrosis of arterioles, interstitial scarring, and tubular atrophy (Fig. 4, opposite). 


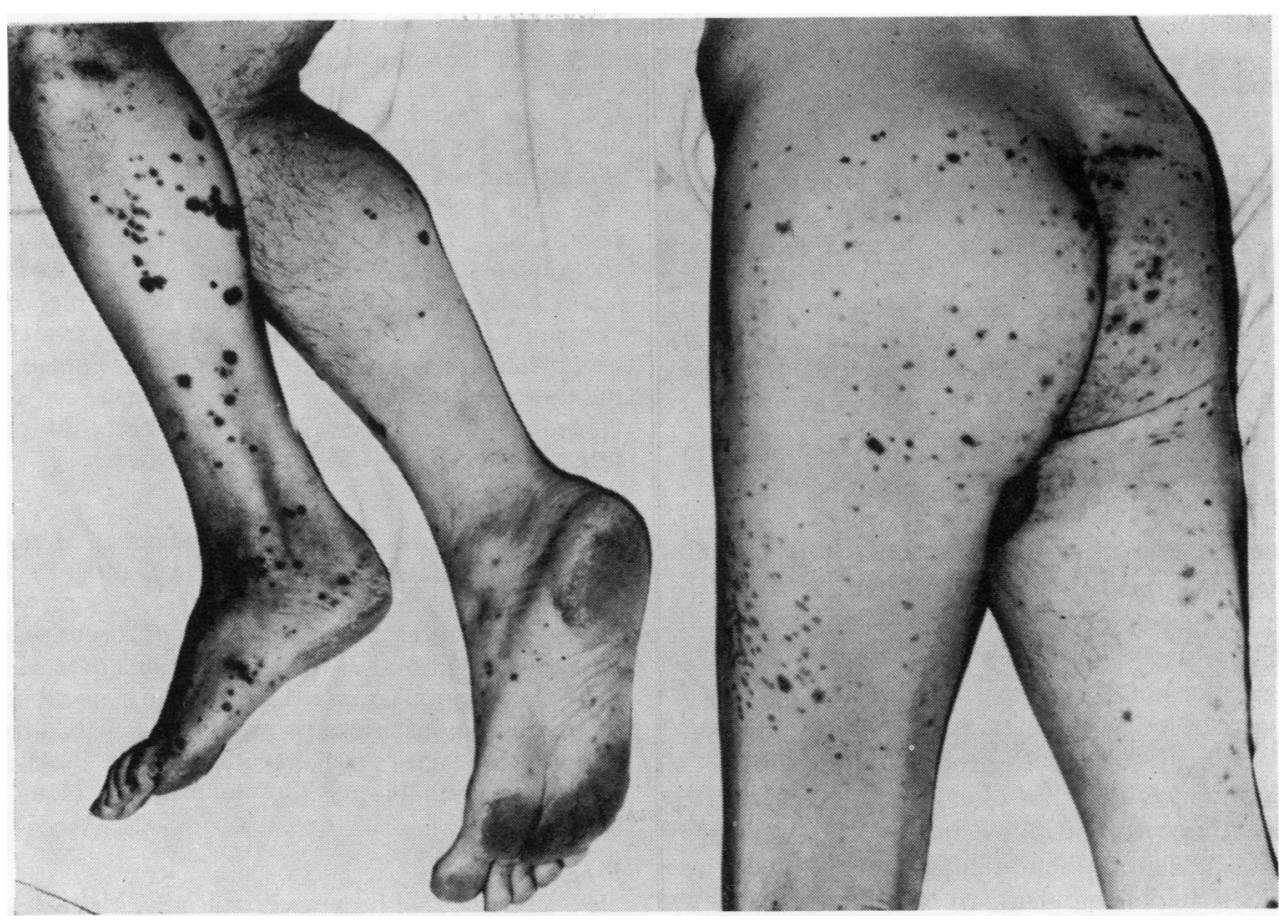

F1G. 3 Case 2. Purpura on buttocks and legs.

을

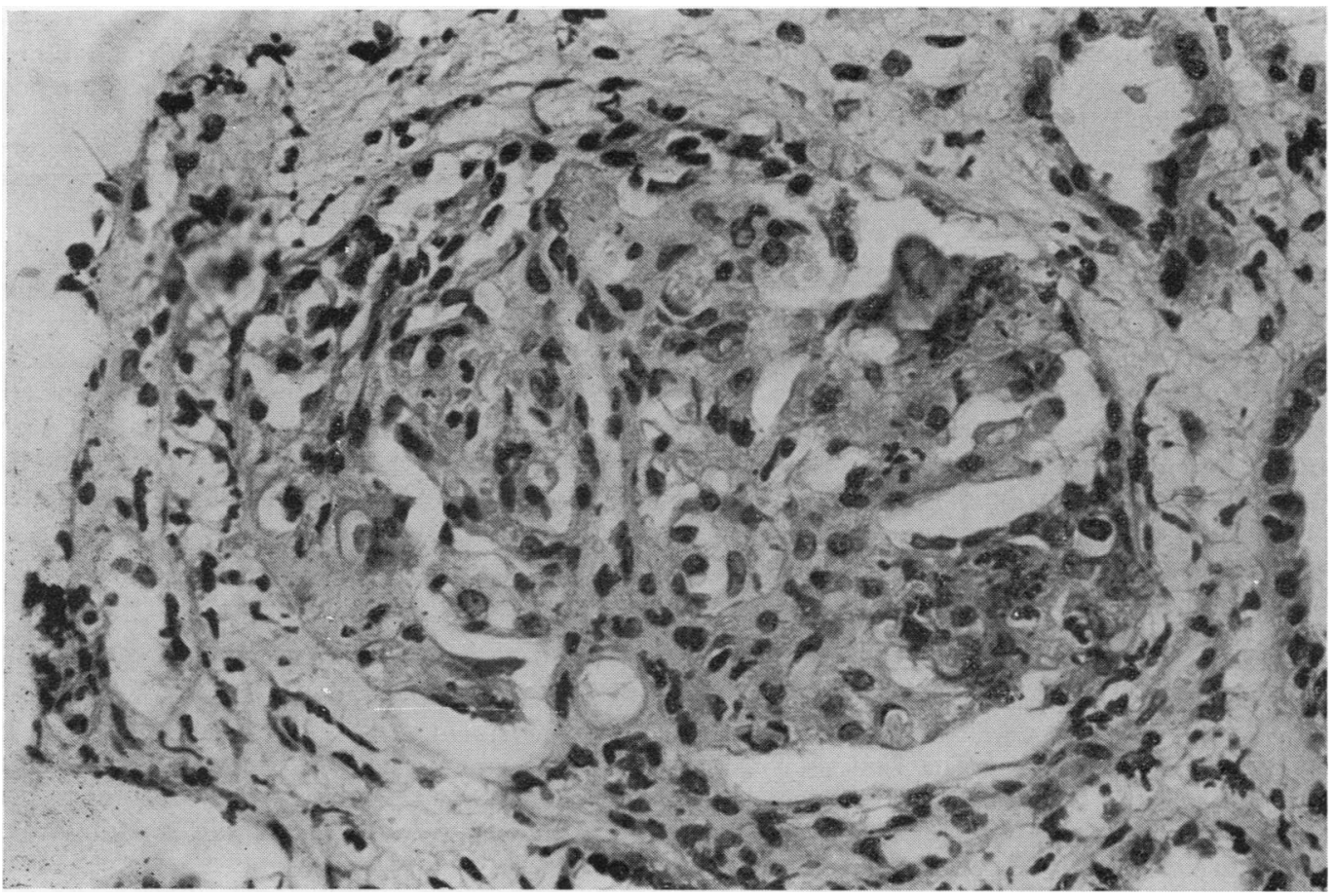

흐.

잉

(1)

용

읔

吾

홍

$\frac{2}{2}$

훙.

을

옥

금

N

กิ

c

足

FIG. 4 Case 2. Histology of renal biopsy, showing changes of acute proliferative glomerulonephritis with tuft necroses and capsular adhesions. Haematoxylin and eosin. $\times 400$ 


\section{Termination}

He was treated with cyclophosphamide but became anuric and died.

\section{Necropsy}

The kidneys were large and pale; there was an infarct in the left kidney with an adjacent perinephric haematoma, resulting from the renal biopsy. Microscopically there was a glomerulonephritis with changes similar to, but more advanced than, those seen in the biopsy. The renal veins were not thrombosed. Uraemic pericarditis, pleural effusions, ascites, and a small healed duodenal ulcer were noted. Arthritic changes were minimal. There were no signs of a generalized arteritis.

\section{Discussion}

The illnesses of both patients were strikingly similar in the sudden appearance, after indomethacin therapy, of purpura associated with necrotizing vasculitis, followed closely by acute glomerulonephritis. However, neither their purpura nor their nephritis can be attributed with certainty to indomethacin. A similar clinical and pathological appearance can follow contact with other allergens, including drugs and streptococci, and may occur in polyarteritis nodosa and Henoch-Schönlein purpura. There was no clinical, bacteriological, or serological evidence of streptococcal infection in either patient; this makes a streptococcal cause unlikely, but does not completely exclude it (Rammelkamp, 1967; Wannamaker, 1970). No clinical or pathological evidence of polyarteritis nodosa was found in other tissues classically involved in this disease. HenochSchönlein purpura is a syndrome of which the aetiology is uncertain; both streptococcal infection and allergy to drugs have been incriminated (Bywaters, 1969) although the evidence for the former is unconvincing (Bywaters, Isdale, and Kempton, 1957; Vernier, Worthen, Peterson, Colle, and Good, 1961). Indomethacin was the only drug taken by the first patient before her illness. The second had received other drugs, of which sodium aurothiomalate seems the most relevant. However, the purpura caused by this is usually thrombocytopenic, and nephrotoxicity from gold is associated with a membranous or 'minimal change' glomerulonephritis (Lee, Dushkin, Eyring, Engleman, and Hopper, 1965; Wilkinson and Eccleston, 1970) rather than the acute proliferative glomerulonephritis which occurred in these cases.

After the discovery of the first two cases the records of all patients admitted with purpura or acute glomerulonephritis to The London Hospital between 1965 and 1969 inclusive (indomethacin having first become available commercially in England in October, 1964) were studied. No other patients were found in whom acute glomerulonephritis, with or without purpura, followed indomethacin therapy. However, two patients were found in whom non-thrombocytopenic purpura may have been caused by this drug.

Case 3, a 60-year-old-man with seropositive rheumatoid arthritis, was treated for one year with indomethacin, initially in the form of suppositories (100 mg. each night) and later orally (25 mg. twice daily). It was then discontinued, but was recommenced 3 months later because the joint pains had become worse. After 10 weeks it was again discontinued in anticipation of his inclusion in a controlled trial of azathioprine. Two days later, before entry into this trial, he suddenly developed a symmetrical maculo-papular purpuric rash on the legs, elbows, and buttocks. There had been no preceding infection and he had taken no other drugs.

\section{Investigations}

$\mathrm{Hb} 12.5 \mathrm{~g} . / 100 \mathrm{ml}$., leucocytes 8,100 per cu. mm. (normal differential), platelets 422,000 per cu. $\mathrm{mm}$. Erythrocyte sedimentation rate $112 \mathrm{~mm}$. $/ \mathrm{hr}$.

No streptococci grown on culture of throat swab; antistreptolysin-O titre less than 200; plasma urea $31 \mathrm{mg} . / 100$ ml., creatinine clearance $126 \mathrm{ml} . / \mathrm{min}$.; no abnormality on microscopy of urine; no proteinuria; latex titre 1:320; antinuclear factor test negative; liver function tests normal. A skin biopsy showed evidence of an allergic vasculitis.

\section{Progress}

He was treated with paracetamol only, his rash subsided in 7 days, and he has since remained well.

Case 4, a 55-year-old-man, was admitted for treatment of a prolapsed intervertebral disc. He was treated with indomethacin, $25 \mathrm{mg}$. twice daily for 7 days, when the drug was withdrawn owing to the development of a non-thrombocytopenic purpura. Although the purpura then subsided rapidly it could not be conclusively attributed to indomethacin as he had also received dichloralphenazone, paracetamol, and procaine penicillin within the previous 3 weeks.

Although over 275,000 people in the United Kingdom are estimated to have been treated with indomethacin since its introduction (Andrew, 1970), most authors have been unable to find evidence that it causes renal damage. Reversible proteinuria with granular casts in the urine (Bruckner and Randle, 1965), haematuria (Stoeber, Sänger, and Kölle, 1968), and slight increases in blood urea (Ballabio, Cirla, Girardi, Caruso, and Colombo, 1963; Norcross, 1963; Thompson, 1964; Michotte and Wauters, 1964) have been noted, but these abnormalities were minor and not well documented. Acute glomerulonephritis has not been reported. Passing mention has been made of purpura (Meyer and Schoenfeld, 1965; Boardman and Hart, 1967; Germain and Gascon, 1968), but its nature has not been established. Although such prolonged treatment as was given in Cases 2 and 3 before the onset of relevant symptoms counts against a causative association, the mechanism of any postulated association is unknown, and similar delayed reactions to other drugs have been reported (Lancaster-Smith, 
1969; Reynolds, Simerville, O'Hara, Hart, and Parkinson, 1969).

Because of the inherent difficulty in excluding other causes of acute glomerulonephritis and purpura, and because two of the cases had received other drugs (as have most patients given indomethacin), we cannot with certainty attribute the abnormalities described to indomethacin. Nevertheless, we feel that the evidence is suggestive and further information concerning such an association should be looked for. This is of particular importance because indomethacin is being used in the treatment of nephrotic syndrome (Michielsen, Verberckmoes, Desmet, and Hermerijckx, 1969).

\section{Summary}

Two patients are described in whom non-thrombocytopenic purpura and a proliferative glomerulonephritis developed during or shortly after indomethacin therapy; both died, one in anuria and the other from a pulmonary embolus. No further examples of glomerulonephritis after indomethacin treatment were found in a retrospective survey of patients admitted to The London Hospital over a 4-year period. However, there were two patients in whom non-thrombocytopenic purpura, without evident renal damage, had developed in relation to treatment with the drug. These are described because, although purpura has occasionally been attributed to the drug, the nature of this condition has not been properly documented. An allergic reaction to indomethacin seems a possible cause of the glomerulonephritis as well as of the purpura in these patients. Further evidence of such an association should be looked for, especially as the drug is being used in the treatment of the nephrotic syndrome.

We are grateful to Prof. J. M. Ledingham for helpful criticism and permission to report Case 1; Dr. D. Vere and Dr. Brian Russell for permission to report their cases; Prof. I. Doniach for help with the pathological interpretation; and Dr. A. Andrew for his co-operation.

\section{References}

ANDREw, A. (1970) Personal communication from Merck, Sharp, and Dohme Ltd.

Ballabio, C. B., Cirla, E., Girardi, G., Caruso, I., and Colombo, B. (1963) Reumatismo, 15, 487 (Clinical and metabolic effects of indomethacin in the treatment of rheumatic diseases).

BRUCKNeR, F. E., AND RANDLE, A. P. H. (1965) Ann. phys. Med., 8, 100 (The use of indomethacin in rheumatoid arthritis).

Bonrdman, P. L., and Hart, F. Dudley (1967) Ann. rheum. Dis., 26, 127 (Side-effects of indomethacin).

Bywaters, E. G. L. (1969) In 'Textbook of the Rheumatic Diseases', ed. W. S. C. Copeman, 4th ed., chap. 11, p. 249. Livingstone, Edinburgh.

—, IsDale, I., AND Kempton, J. J. (1957) Quart. J. Med., 50 (n.s. 26), 161 (Schönlein-Henoch purpura. Evidence for a Group A $\beta$-haemolytic streptococcal aetiology).

Germain, G., and Gascon, J. (1968) In 'Proceedings of the 2nd Laurentian Rheumatology Conference; International Symposium on Non-Steroid Anti-Inflammatory Compounds'. Ste. Marguerite, Quebec, Canada, 1966 (Indomethacin: clinical and biological study carried out in 73 patients).

LANCASTER-Smith, M. J. (1969) Lancet, 2, 1011 (Delayed reaction to Phenindione).

Lee, J. C., Dushkin, M., Eyring, E. J., Engleman, E. P., ANd Hopper, J. (1965) Arthr. and Rheum., 8, 1 (Renal lesions associated with gold therapy: light and electron microscopic studies).

MEYER, E., AND SCHOENFELD, L. S. (1965) Schweiz. med. Wschr., 95, 1722 (Indomethacin in the treatment of rheumatic diseases).

Michielsen, P., Verberckmoes, R., Desmet, V., ANd Hermeridckx, W. (1969) J. Urol. Nephrol., 75, 315 (Histological evolution of diffuse proliferative glomerulonephritis treated by indomethacin).

Michorte, L. J., AND WAUTERS, M. (1964) Acta rheum. scand., 10, 273 (Clinical test of indomethacin).

NorCRoss, B. M. (1963) 'An extended study of indomethacin', in 'Annual Meeting of the American Rheumatism Association (Atlantic City)'. Quoted by Rothermich (1966). (Abstr. Arthr. and Rheum., 6, 290).

Rammelkamp, C. H. (1967) In 'Renal Disease', ed. D. A. K. Black, 2nd ed., chap. 8, p. 209. Blackwell Scientific Publications, Oxford.

Reynolds, R. D., Simerville, J. J., O’Hara, D. D., Hart, J. B., and Parkinson, J. E. (1969) J. Urol. (Baltimore), 101, 45 (Hemorrhagic cystitis due to cyclophosphamide).

ROTHERMICH, N. O. (1966) J. Amer. med. Ass., 195, 531.

Stoeber, E., Sänger, L., AND Kölle, G. (1968) Münch. med. Wschr., 110, 548 (Treatment of juvenile rheumatic arthritis with indomethacin).

Thompson, M. (1964) Rhumatologie, 16, 439 (Method of using indomethacin in the treatment of rheumatic diseases).

Vernier, R. L., Worthen, H. G., Peterson, R. D., Colle, E., AND Good, R. A. (1961) Pediatrics, 27, 181 (Anaphylactoid purpura. I. Pathology of the skin and kidney and frequency of streptococcal infection).

WanNamaker, L. W. (1970) New Engl. J. Med., 282, 78 (Differences between streptococcal infections of the throat and of the skin).

Wilkinson, R., AND ECCLESTon, D. W. (1970) Brit. med. J., 2, 772 (Nephrotic syndrome induced by gold therapy). 